Article

\title{
Multiresponse Optimization of Cutting Force and Cutting Power in Chopping Agricultural Residues Using Grey-Based Taguchi Method
}

\author{
Van-Dam Vu ${ }^{1}$, Thanh-Toan Nguyen ${ }^{2}$, Ngoc-Hung Chu ${ }^{3}$, Quoc-Huy Ngo ${ }^{4}$, Ky-Thanh $\mathrm{Ho}^{4}$ and \\ Van-Du Nguyen $4, *$ (D) \\ 1 Administration Office, Thai Nguyen University, 3/2 Street, Tichluong Ward, Thainguyen City 251750, \\ Vietnam; vudam@tnu.edu.vn \\ 2 Information and Library Center, Thai Nguyen University of Technology, 3/2 Street, Tichluong Ward, \\ Thainguyen City 251750, Vietnam; nguyenthanhtoan@tnut.edu.vn \\ 3 Faculty of International Training, Thai Nguyen University of Technology, 3/2 Street, Tichluong Ward, \\ Thainguyen City 251750, Vietnam; chungochung@tnut.edu.vn \\ 4 Faculty of Mechanical Engineering, Thai Nguyen University of Technology, 3/2 street, Tichluong Ward, \\ Thainguyen City 251750, Vietnam; ngoquochuy24@gmail.com (Q.-H.N.); hkythanh@tnut.edu.vn (K.-T.H.) \\ * Correspondence: vandu@tnut.edu.vn; Tel.: +84-91-605-6618
}

Received: 29 January 2020; Accepted: 24 February 2020; Published: 25 February 2020

\begin{abstract}
Agricultural residues are the most abundant biomass and forage resources. Chopping is a precondition for either use, and reducing the shearing force has been considered as one of the most effective way to save energy. A smaller force can also permit more compact mechanical parts of chopping devices. In several cases, power consumption may be large, even when the shearing force is small, if the corresponding cutting velocity is high. Consequently, it is important to minimize both cutting force and power consumption simultaneously. This paper presents a practical approach to solve the multi-objective optimization problem for chopping processes of corn stalks. Applying the Taguchi design of experiments, a plan of 27 chopping tests was conducted. Based on the grey relational grade analysis and analysis of variance technique, optimum levels as well as the percentage contribution of such parameters were identified. Experimental results showed that the multi-response optimization problem in chopping corn stalks can be effectively addressed through the combination of Taguchi design and grey relational analysis. The results can be expanded for practical applications in design and operation of chopping machines for agricultural residues.
\end{abstract}

Keywords: forage chopping; biomass; cutting force; cutting power; multi-objective optimization; grey-based Taguchi

\section{Introduction}

Agricultural residues are the most important resources for biomass and animal feeding. Size reduction is an important prerequisite to produce forage and biomass energy. Nevertheless, this procedure was also considered as one of the most energy-inefficient tasks [1,2]. The efficiency of the size reduction has typically been assessed through the amount of cutting force and energy required [3-5]. It has been found that equipment using shear mode for size reduction may hold promise for improved energy efficiency [6]. The energy required for cutting forage stems has been evaluated for a wide range of plant species, cutting velocities, moisture contents, and stem sizes [7]. The results were classified into three categories [8]: quasistatic shearing (cutting velocities less than $30 \mathrm{~mm} / \mathrm{s}$ ), cutting with a counter-edge (at velocities greater than $0.5 \mathrm{~m} / \mathrm{s}$ ), and impact cutting without a counter-edge (at speeds up to $60 \mathrm{~m} / \mathrm{s}$ ). It has been shown that minimal energy is required for quasistatic 
shearing and for cutting with a counter-edge. Prasad and Gupta [9] found specific energies for corn stalks in the range of $19-24 \mathrm{~mJ} / \mathrm{mm}^{2}$ in quasistatic measurements. However, the energies required for impact cutting are generally 1 or 2 orders of magnitude greater than those recorded for quasistatic or counter-edge cutting [8].

Quasistatic tests have been used in many studies of cutting force and cutting energy for various kinds of agricultural residues. For example, the change of shear force and energy of cotton stalk were evaluated by Pekitkan and Eliçin [10]. Another quasistatic test using a universal machine was implemented to study the effects of diameter and age of grape canes on cutting force and energy [11]. Using the same experimental apparatus, the effects of moisture content, internode region, and oblique angle on the mechanical properties of sainfoin stem were evaluated by Boydaş et al. [12]. Other authors [13] found that the shearing angle has a strong effect on the cutting force and specific energy. A smaller cutting angle was related to a larger cutting resistance.

Impact cutting tests have been investigated in many studies, where the effect of various factors on the force and energy were evaluated. For corn stalks, Prasad and Gupta [9] showed that the optimum values of bevel angle, knife approach angle, and shear angle providing the minimum cutting force and energy consumption were $23^{\circ}, 32^{\circ}$, and $55^{\circ}$, respectively. An investigation by Azadbakht and Zahedi [4] showed that the effects of height, moisture content, and their interaction on cutting energy are significant. The energy consumption during impact cutting of canola stalk [14] was considered as a function of moisture content and cutting height.

Generally, agricultural chopping systems are designed based on two main cutting principles: scissor shearing to provide shear stress, and rotary knives to generate both impact and shear stress on the stalks [15]. For the first case, the plants to be cut are pressed against the fixed counter edge with the help of cutter. The knife speed is resolved into two components: chopping speed, which penetrates into the material, and the sliding cut speed [16].

The analysis of the literature above indicates that cutting speed and blade geometry have strong effects on cutting force and cutting energy for agricultural residues. Most of the investigations had been done for impact cutting with a single knife. Several others have functioned with counter edge cutting but under quasistatic mode, where the cutting velocity is extremely low. There have been few studies on chopping processes with counter edges and under high-velocity conditions. Besides, it is worth noting that the power consumption may be large, even when the shearing force is small, if the corresponding cutting velocity is high. Consequently, it is expected to minimize both cutting force and power consumption simultaneously. A recent investigation with such purpose was conducted using factorial experimental designs [17]. The main aims of this study are to provide another approach of solving such problem by using Taguchi-grey relational analysis technique. The Taguchi method with grey relational analysis (GRA) has been employed in several experimental investigations in agriculture and biotechnology [18-21]. However, there has not been found a similar study for optimization of chopping agricultural residues.

\section{Materials and Methods}

\subsection{Experimental Setup}

The setup was made based on the outline of a 93ZP-1000 straw chopper produced by the Liaoning Fengcheng Donfeng Machinery Factory (Liaoning, Dandong, China). Figure 1 illustrates a 3D model of the chopping device.

In Figure 1, a belt wheel (1) receives and transfers drive torque from a Direct-current (DC) motor to the cutting knifes (3) via the main spindle (2). Being made in the form of a circular sector, the cutter can be easily adjusted to obtain a required approach angle $\alpha$ by using the screw (4) and the clamp set (5). In the figure, the position of the stalk to be cut (6) is determined by two angles: the feed angle $\beta$ and the tilt angle $\varphi$. In this study, the tilt angle $\varphi$ remained at $90^{\circ}$. 


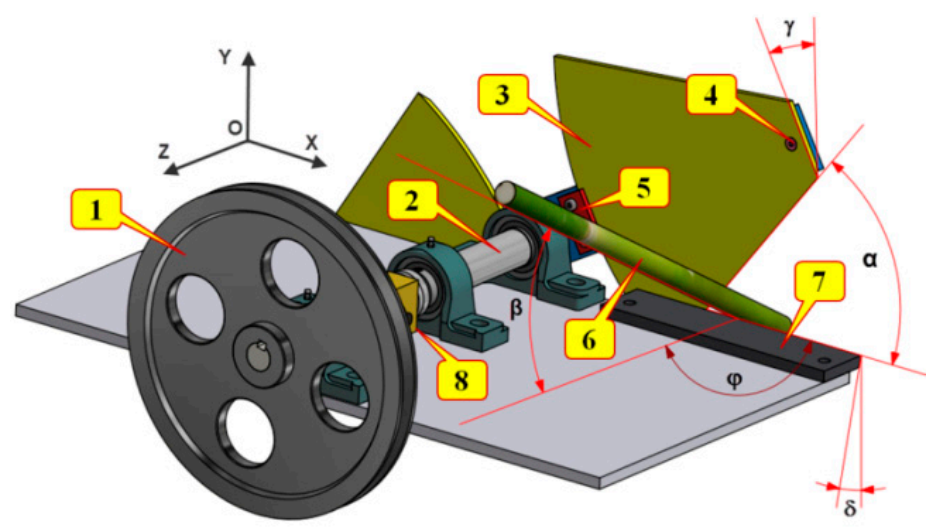

Figure 1. A 3D model of the experimental setup. (1) belt wheel; (2) spindle shaft; (3) knife; (4) screw; (5) clamp; (6) maize stalk; (7) counter shear; (8) torque sensor.

The experimental setup was then implemented as illustrated in Figure 2. In this figure, all parts are labelled similar to those in Figure 1. As mentioned, the approach angle $\alpha$ is adjusted by the screw (4) and the clamp set (5) (Figure 2a). In addition, a dynamic force sensor (9) is used to measure instant cutting force. In Figure $2 b$, the way to adjust the feed angle $\beta$ by the clamp set (10) is illustrated.

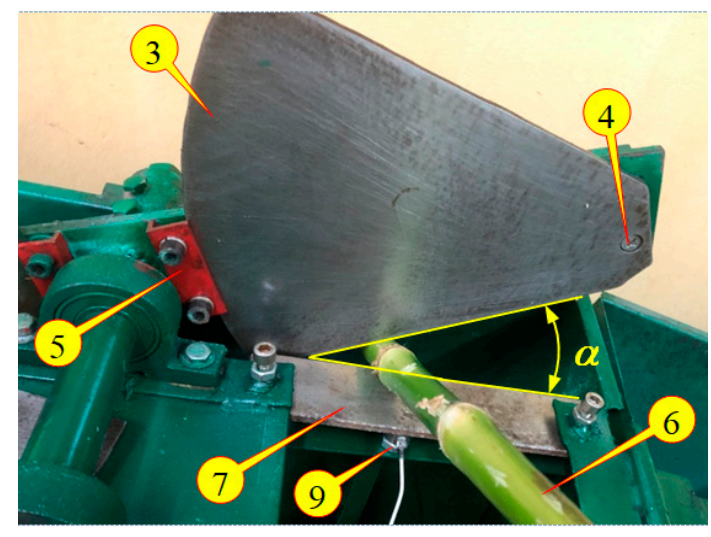

(a)

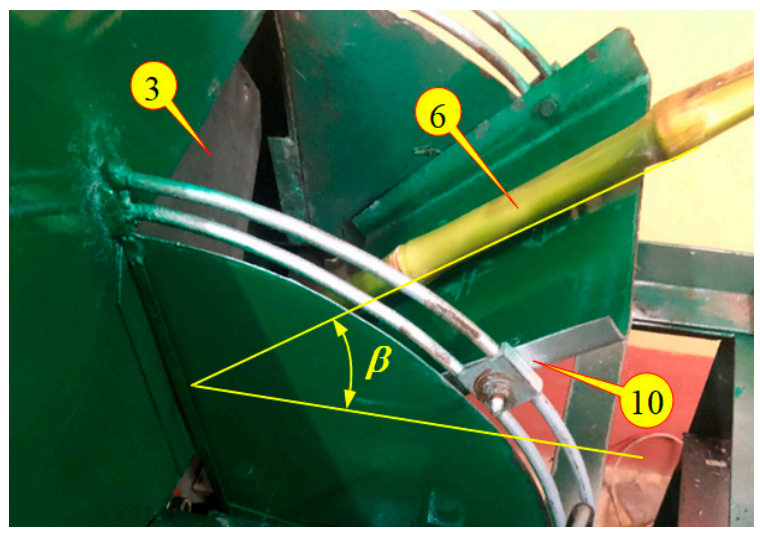

(b)

Figure 2. Practical experimental setup: (a) a front view (the protection cover was opened) and (b) a side view: (3) knife; (4) screw; (5) clamp; (6) maize stalk; (7) counter shear; (8) torque sensor; (9) force sensor and (10) clamp set.

The force sensor model 9712A500 (Kistler, Winterthur, Switzerland), with sensitivity of $2.4729 \mathrm{mV} / \mathrm{N}$, was placed under the counter shear bar to measure the cutting force. A DAQ model NI-USB-6008 (National Instruments, Austin, Texas, USA) and the Ni Signal Express software were employed to collect the cutting force data. The experimental rig was driven by a commercial $1.5 \mathrm{~kW}$ DC motor, working with a voltage supply ranging from 50 to $220 \mathrm{~V}$. By adjusting the voltage provided by an Alternating-current $(\mathrm{AC})$ variable transformer combined with a rectifier, the variable speed of the cutting spindle could be obtained. The maize stalks used for this experimental study were kept in an air-conditioned room for one week after harvest from the fields in the northern part of Vietnam. The wet basis moisture content of the samples was then measured by drying-weighting method. The wet basis moisture content was around $81 \%$. 


\subsection{The Multiobjective Function}

The average power consumption is the amount of energy consumed per unit time. Consequently, given a cutting force $F c$ and the corresponding cutting velocity $V$, the cutting power $P c$ can be expressed as:

$$
P_{c}=F_{c} \times V
$$

In chopping machines, where a number of knifes are equally arranged on a rotating disk, the cutting force signal appears as a train of periodic, near identical pulses, as shown in Figure 3a. The peaks of the cutting force signal were collected for this experimental study.

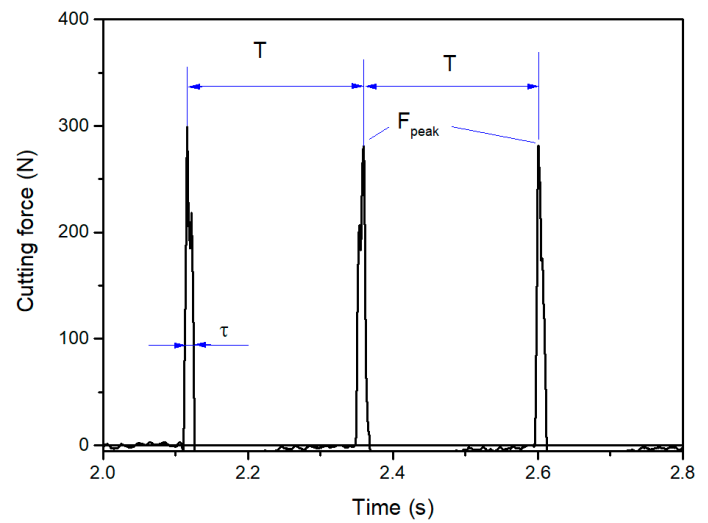

(a)

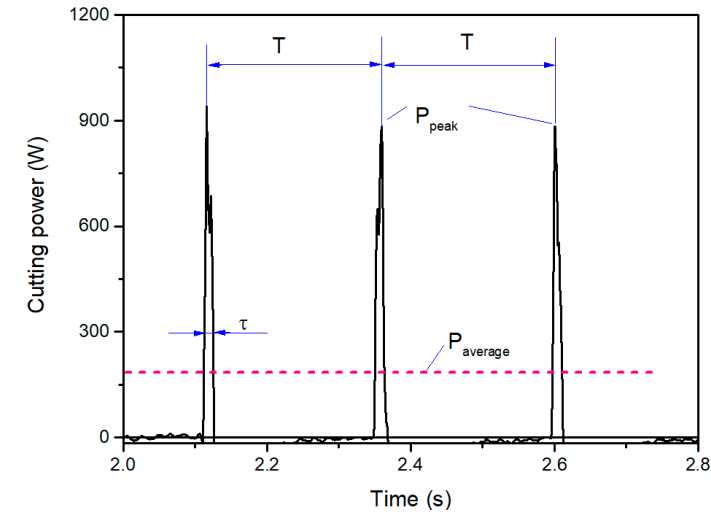

(b)

Figure 3. Example of experimental cutting force and power consumption signals.

With the chopping disk driven by an electrical motor, it can be assumed that the cutting velocity is approximately constant during each cutting process. Applying Equation (1), the instantaneous cutting power at a function of time can be obtained from the cutting force signal, as shown in Figure 3b.

Denoting the period as $T$, i.e., the time between two consecutive chopping processes, the energy consumed for cutting during such time can be expressed as:

$$
E_{\text {pulse }}=\int_{0}^{T} p(t) d t
$$

The total consumed power then can be calculated by:

$$
P=\frac{1}{T} \int_{0}^{T} p(t) d t=\frac{E_{\text {pulse }}}{T}
$$

denoting the pulse time as $\tau$ so that:

$$
E_{\text {pulse }}=P_{\text {penk }} \times \tau
$$

The duty cycle of the pulse train then can be defined as:

$$
\frac{P}{P_{\text {peak }}}=\frac{\tau}{T}
$$

In this study, the duration of each cutting pulse is approximately calculated as the time required for a point on the cutting edge to completely pass the stalk diameter. To simplify the calculation, the stalk diameters are assumed to be their average value and thus a constant, assigned as $d_{\text {average }}$. In this study, $d_{\text {average }}$ was set to be $0.02 \mathrm{~m}$. Consequently, the pulse time $\tau$ is defined as: 


$$
\tau=\frac{d_{\text {average }}}{V}
$$

Finally, the power consumption at a certain cutting velocity $V$ can be calculated as:

$$
P=\frac{\tau}{T} P_{\text {peak }}=\frac{d_{\text {average }}}{V \cdot T} F_{\text {peak }} . V=\frac{1}{T} d_{\text {average }} \cdot F_{\text {peak }}
$$

To simplify the notation in the experimental analysis, the peak value of the cutting force in each chopping event will be considered as demonstrative of cutting force and thus will be noted as the cutting force $F$ in this study. Consequently, the multiobjective optimisation problem can be expressed as:

$$
\min (F(\alpha, \beta, V), P(\alpha, \beta, V))
$$

\subsection{Design of Experiments and Multiobjective Optimization Process}

In this study, the approach angle, the feed angle and the cutting velocity were selected to be three experimental variables. The design of experiments was built using three parameters at three levels each, leading to the $\operatorname{L} 27\left(3^{3}\right)$ orthogonal array of tests. The investigated parameters and their levels considered in this study are shown in Table 1.

Table 1. Experimental parameters and their levels

\begin{tabular}{cccc}
\hline \multirow{2}{*}{ Parameters } & \multicolumn{3}{c}{ Input Parameter Levels } \\
\cline { 2 - 4 } & Level 1 & Level 2 & Level 3 \\
\hline Velocity $(\mathrm{m} / \mathrm{s}), V$ & 4.40 & 5.66 & 6.91 \\
Approach angle $\left({ }^{\circ}\right), \alpha$ & 0 & 30 & 60 \\
Feeding angle $\left({ }^{\circ}\right), \beta$ & 0 & 25 & 50 \\
\hline
\end{tabular}

As mentioned, the two objective responses, including peak values of cutting force and cutting power, were selected for the optimization process. Once the normalized signal-to-noise $(\mathrm{S} / \mathrm{N})$ ratio values of the responses were calculated, corresponding grey relational coefficients were carried out. The grey relational analysis was then implemented in order to find the trade-off optimum condition. Detailed steps of calculation techniques and results are presented in the next section.

\section{Results and Discussions}

\subsection{Step 1: Calculate the S/N Ratios}

Firstly, the $\mathrm{S} / \mathrm{N}$ ratio for the corresponding responses was calculated. Since minimization of all outputs is intended, the following formula for the case of smaller-the-better was employed:

$$
S / N(\eta)=-10 \log _{10}\left(\frac{1}{n} \sum_{i=1}^{n} y_{i j}^{2}\right)
$$

where $n$ is number of replications, $y_{i j}$ is observed response value, $I=1,2, \ldots, n ; j=1,2, \ldots, \mathrm{k}$.

Table 2 shows the input factor values and output responses of all 27 tests which were planned by the Taguchi design, where each set of inputs was replicated three times, and the corresponding $\mathrm{S} / \mathrm{N}$ ratios calculated using the Equation (9). The cutting force was measured by the force sensor. The cutting power was calculated using Equation (7). 
Table 2. The L27 orthogonal array, experimental results and corresponding signal-to-noise $(\mathrm{S} / \mathrm{N})$ ratios.

\begin{tabular}{cccccccc}
\hline & \multicolumn{3}{c}{ Input Factors } & \multicolumn{2}{c}{ Responses } & \multicolumn{2}{c}{ S/N Ratios } \\
\cline { 2 - 7 }$\#$ & $\boldsymbol{V}(\mathbf{m} / \mathbf{s})$ & $\left.\boldsymbol{\alpha} \mathbf{(}^{\circ}\right)$ & $\left.\boldsymbol{\beta} \mathbf{(}^{\circ}\right)$ & Force $\mathbf{( N )}$ & Power $\mathbf{( W )}$ & Force & Power \\
\hline 1 & 4.40 & 0 & 0 & 706.07 & 82.3748 & -56.977 & -38.316 \\
2 & 4.40 & 0 & 0 & 617.68 & 72.0627 & -55.815 & -37.154 \\
3 & 4.40 & 0 & 0 & 502.10 & 58.5788 & -54.016 & -35.355 \\
4 & 4.40 & 30 & 25 & 313.99 & 36.6322 & -49.938 & -31.277 \\
5 & 4.40 & 30 & 25 & 264.13 & 30.8152 & -48.436 & -29.775 \\
6 & 4.40 & 30 & 25 & 276.60 & 32.2700 & -48.837 & -30.176 \\
7 & 4.40 & 60 & 50 & 261.94 & 30.5597 & -48.364 & -29.703 \\
8 & 4.40 & 60 & 50 & 269.80 & 31.4767 & -48.621 & -29.960 \\
9 & 4.40 & 60 & 50 & 263.60 & 26.3200 & -48.419 & -28.406 \\
10 & 5.66 & 0 & 25 & 485.10 & 72.7650 & -53.717 & -37.238 \\
11 & 5.66 & 0 & 25 & 479.44 & 71.9160 & -53.615 & -37.137 \\
12 & 5.66 & 0 & 25 & 414.84 & 62.2260 & -52.358 & -35.879 \\
13 & 5.66 & 30 & 50 & 312.86 & 46.9290 & -49.907 & -33.429 \\
14 & 5.66 & 30 & 50 & 255.07 & 38.2605 & -48.133 & -31.655 \\
15 & 5.66 & 30 & 50 & 242.60 & 36.3900 & -47.698 & -31.220 \\
16 & 5.66 & 60 & 0 & 287.93 & 43.1895 & -49.186 & -32.708 \\
17 & 5.66 & 60 & 0 & 267.53 & 40.1295 & -48.547 & -32.069 \\
18 & 5.66 & 60 & 0 & 261.87 & 39.2805 & -48.362 & -31.884 \\
19 & 6.91 & 0 & 50 & 344.59 & 63.1748 & -50.746 & -36.011 \\
20 & 6.91 & 0 & 50 & 317.39 & 58.1882 & -50.032 & -35.297 \\
21 & 6.91 & 0 & 50 & 289.06 & 52.9943 & -49.220 & -34.485 \\
22 & 6.91 & 30 & 0 & 307.19 & 56.3182 & -49.748 & -35.013 \\
23 & 6.91 & 30 & 0 & 273.20 & 50.0867 & -48.730 & -33.994 \\
24 & 6.91 & 30 & 0 & 250.53 & 45.9305 & -47.977 & -33.242 \\
25 & 6.91 & 60 & 25 & 385.38 & 70.6530 & -51.718 & -36.983 \\
26 & 6.91 & 60 & 25 & 361.59 & 66.2915 & -51.164 & -36.429 \\
27 & 6.91 & 60 & 25 & 317.39 & 58.1882 & -50.032 & -35.297 \\
\hline & & & & & & &
\end{tabular}

\subsection{Step 2: Calculate Normalized S/N Ratios and Grey Relational Coefficients}

In order to formulate the data for the grey relation analysis, $\mathrm{S} / \mathrm{N}$ ratios were then normalized. An appropriate value is deducted from the values in the same array to make the value approximate to 1 . The normalized $\mathrm{S} / \mathrm{N}$ ratios were calculated for $\mathrm{S} / \mathrm{N}$ ratio with smaller-the-better manner, using the following expression:

$$
Z_{i j}=\frac{\max \left(y_{i j}, i=1,2, \ldots n\right)-y_{i j}}{\max \left(y_{i j}, i=1,2, \ldots n\right)-\min \left(y_{i j}, i=1,2, \ldots n\right)}
$$

The normalized $\mathrm{S} / \mathrm{N}$ ratio values obtained were then used to calculate the grey relational coefficients by using the following formula:

$$
\gamma\left(y_{0}(k), y_{i}(k)\right)=\frac{\Delta \min +\xi \Delta \max }{\Delta_{0 j}(k)+\xi \Delta \max }
$$

where $j=1,2, \ldots, n ; k=1,2, \ldots, m ; n$ is the number of experimental data items and $m$ is the number of responses; $y_{0}(k)$ is the reference sequence; $y_{i}(k)$ is the specific comparison sequence; $\Delta_{0} j$ is the absolute value of the difference between $y_{0}(k)$ and $y_{j}(k) ; \Delta \min$ and $\Delta$ max are the smallest and largest values of $y_{i}(k)$, respectively; $\xi$ is the distinguishing coefficient, $0 \leq \xi \leq 1$.

The normalized $\mathrm{S} / \mathrm{N}$ ratio values and the corresponding grey relational coefficients are given in Table 3. 
Table 3. Normalized values of $\mathrm{S} / \mathrm{N}$ ratios and grey relational coefficients.

\begin{tabular}{|c|c|c|c|c|c|c|}
\hline \multirow[t]{2}{*}{ \# } & \multicolumn{2}{|c|}{ Normalized Values of S/N Ratios } & \multicolumn{2}{|c|}{ Grey Relational Coefficients } & \multirow{2}{*}{$\begin{array}{c}\text { Grey Grade } \\
0.333\end{array}$} & \multirow{2}{*}{$\begin{array}{c}\text { Order } \\
27\end{array}$} \\
\hline & 0.000 & 0.000 & 0.333 & 0.333 & & \\
\hline 2 & 0.125 & 0.117 & 0.364 & 0.362 & 0.363 & 26 \\
\hline 3 & 0.319 & 0.299 & 0.423 & 0.416 & 0.420 & 23 \\
\hline 4 & 0.758 & 0.710 & 0.674 & 0.633 & 0.654 & 11 \\
\hline 5 & 0.920 & 0.862 & 0.863 & 0.783 & 0.823 & 3 \\
\hline 6 & 0.877 & 0.821 & 0.803 & 0.737 & 0.770 & 6 \\
\hline 7 & 0.928 & 0.869 & 0.874 & 0.792 & 0.833 & 2 \\
\hline 8 & 0.900 & 0.843 & 0.834 & 0.761 & 0.798 & 5 \\
\hline 9 & 0.922 & 1.000 & 0.865 & 1.000 & 0.933 & 1 \\
\hline 10 & 0.351 & 0.109 & 0.435 & 0.359 & 0.397 & 25 \\
\hline 11 & 0.362 & 0.119 & 0.439 & 0.362 & 0.401 & 24 \\
\hline 12 & 0.498 & 0.246 & 0.499 & 0.399 & 0.449 & 22 \\
\hline 13 & 0.762 & 0.493 & 0.677 & 0.497 & 0.587 & 15 \\
\hline 14 & 0.953 & 0.672 & 0.914 & 0.604 & 0.759 & 7 \\
\hline 15 & 1.000 & 0.716 & 1.000 & 0.638 & 0.819 & 4 \\
\hline 16 & 0.840 & 0.566 & 0.757 & 0.535 & 0.646 & 12 \\
\hline 17 & 0.908 & 0.630 & 0.845 & 0.575 & 0.710 & 10 \\
\hline 18 & 0.928 & 0.649 & 0.875 & 0.588 & 0.731 & 8 \\
\hline 19 & 0.671 & 0.233 & 0.603 & 0.394 & 0.499 & 19 \\
\hline 20 & 0.748 & 0.305 & 0.665 & 0.418 & 0.542 & 17 \\
\hline 21 & 0.836 & 0.387 & 0.753 & 0.449 & 0.601 & 14 \\
\hline 22 & 0.779 & 0.333 & 0.693 & 0.429 & 0.561 & 16 \\
\hline 23 & 0.889 & 0.436 & 0.818 & 0.470 & 0.644 & 13 \\
\hline 24 & 0.970 & 0.512 & 0.943 & 0.506 & 0.725 & 9 \\
\hline 25 & 0.567 & 0.134 & 0.536 & 0.366 & 0.451 & 21 \\
\hline 26 & 0.626 & 0.190 & 0.572 & 0.382 & 0.477 & 20 \\
\hline 27 & 0.748 & 0.305 & 0.665 & 0.418 & 0.542 & 18 \\
\hline
\end{tabular}

\subsection{Step 3: Perform Analysis of Variance (ANOVA)}

Analysis of variance (ANOVA) was performed to identify the effect of individual factors. The percentage of contribution calculated from ANOVA can be used to estimate the importance of each parameter on the performance responses. The results of ANOVA and contribution of each factor are depicted in the Table 4.

Table 4. Analysis of variance for means.

\begin{tabular}{cccccccc}
\hline Source & $\begin{array}{c}\text { Degree of } \\
\text { Freedom }\end{array}$ & Seq SS & Adj SS & Adj MS & F Value & P Value & $\begin{array}{c}\text { Contribution } \\
(\%)\end{array}$ \\
\hline$V$ & 2 & 0.01450 & 0.01450 & 0.007251 & 0.46 & 0.683 & 7 \\
$\alpha$ & 2 & 0.12327 & 0.12327 & 0.061635 & 3.94 & 0.203 & 58 \\
$\beta$ & 2 & 0.04370 & 0.04370 & 0.021850 & 1.40 & 0.417 & 21 \\
Residual Error & 2 & 0.03130 & 0.03130 & 0.015652 & & & \\
Total & 8 & 0.21278 & & & & & \\
\hline
\end{tabular}

As can be seen from Table 4, the approach angle has the most significant effect on the responses $(58 \%)$, followed by the feed angle $(22 \%)$ and then the spindle speed $(7 \%)$.

\subsection{Step 4: Calculate Grey Relational Grades and Determine the Optimum Cutting Condition}

Next, the grey relational grades were calculated using the following formula:

$$
\overline{\gamma_{j}}=\frac{1}{k} \sum_{i=1}^{m} \gamma_{i j}
$$


Table 5 shows the grey relational grades with respect to the different levels of input parameters. Since the higher grey relational grade indicates a better product quality, the optimal level for each input parameter was determined as the highest value in the investigated range. Such values were underlined in Table 5. The data were then plotted Figure 4.

Table 5. Corresponding grey relational grades of the tests.

\begin{tabular}{cccc}
\hline Level & $\boldsymbol{V}$ & $\boldsymbol{\alpha}$ & $\boldsymbol{\beta}$ \\
\hline 1 & 0.6584 & 0.4449 & 0.5703 \\
2 & 0.6110 & 0.7045 & 0.5514 \\
3 & 0.5601 & 0.6801 & 0.7078 \\
Delta & 0.0983 & 0.2596 & 0.1563 \\
Rank & 3 & 1 & 2 \\
\hline
\end{tabular}

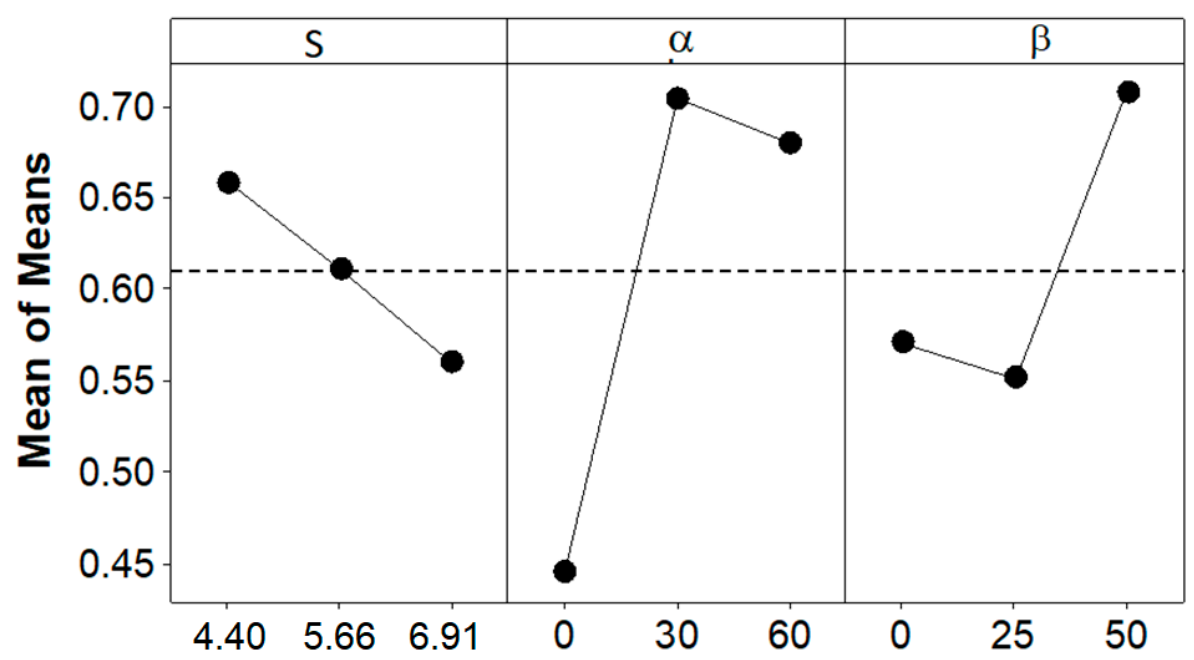

Figure 4. Factor effects on grade values.

In conclusion, the optimum parameters for minimizing both cutting force and cutting power were determined as follows: the velocity was at level 1, i.e., $4.40 \mathrm{~m} / \mathrm{s}$; the approach angle was at level 2 , i.e., at $30^{\circ}$, and the feeding angle was at level 3 , i.e., at $50^{\circ}$. Doing validation tests with the above optimum inputs, a cutting force of $251.7 \mathrm{~N}$ and cutting power of $26.2 \mathrm{~W}$ were obtained. Looking back at the 27 tests run before, as shown in Table 2, there were two tests (number 9 and number 15) that would be considered as providing either the smallest force or smallest power. For comparison purpose, the inputs and response values of these two tests and the optimum set are represented in Table 6.

Table 6. The optimum test compared to two normal tests.

\begin{tabular}{cccccc}
\hline Test No. & $\mathbf{V ~ ( m / s )}$ & $\boldsymbol{\alpha}\left(^{\circ}\right)$ & $\boldsymbol{\beta}\left(^{\circ}\right)$ & $\mathbf{F ~ ( N )}$ & $\mathbf{P}(\mathbf{W})$ \\
\hline 9 & 4.40 & 60 & 50 & 263.60 & 26.3200 \\
15 & 5.66 & 30 & 50 & 242.60 & 36.3900 \\
Optimum & 4.4 & 30 & 50 & 251.7 & 26.2 \\
\hline
\end{tabular}

As can be seen in Table 6, the test number 9 provided the smallest cutting power, compared to other 26 tests, with $\mathrm{P}=26.32 \mathrm{~W}$. However, the cutting force at that condition was of $263.6 \mathrm{~N}$, higher than that of other tests. Similarly, the test number 15 gave the smallest cutting force as $242.6 \mathrm{~N}$ but with a high cutting power of $36.39 \mathrm{~W}$. The optimum input (shown in the last row of the table) provided a combination of both relatively small cutting force $(251.7 \mathrm{~N})$ and cutting power $(26.2 \mathrm{~W})$. 


\section{Conclusions}

In chopping of agricultural residues, the cutting force can decrease at higher velocity, but high velocity would also lead to increased power consumption. The optimum parameters of this multiresponse problem in chopping corn stalks can be determined by employing Taguchi experimental design combined with grey relational analysis. The cutting force and cutting power thus can both reach the smallest values.

Author Contributions: Conceptualization, V.-D.V., K.-T.H. and V.-D.N.; Data curation, T.-T.N., N.-H.C. and Q.-H.N.; Formal analysis, T.-T.N., N.-H.C. and K.-T.H.; Investigation, V.-D.V.; Methodology, N.-H.C. and V.-D.N.; Resources, T.-T.N.; Software, Q.-H.N.; Supervision, V.-D.N. All authors have read and agreed to the published version of the manuscript.

Funding: This research received no external funding.

Acknowledgments: The authors would like to express their thanks to Thai Nguyen University and TNU University of Technology (Thai Nguyen University of Technology) for all supports and encouragements.

Conflicts of Interest: The authors declare no conflict of interest.

\section{References}

1. Mohsenin, N.N. Physical Properties of Plant and Animal Materials: Structure, Physical Characteristics, and Mechanical Properties; Gordon and Breach: London, UK, 1986.

2. Bitra, V.S.; Womac, A.; Igathinathane, C.; Miu, P.I.; Yang, Y.T.; Smith, D.R.; Chevanan, N.; Sokhansanj, S.; Cannayen, I. Direct measures of mechanical energy for knife mill size reduction of switchgrass, wheat straw, and corn stover. Bioresour. Technol. 2009, 100, 6578-6585. [CrossRef] [PubMed]

3. Igathinathane, C.; Pordesimo, L.; Schilling, M.; Columbus, E. Fast and simple measurement of cutting energy requirement of plant stalk and prediction model development. Ind. Crop. Prod. 2011, 33, 518-523. [CrossRef]

4. Azadbakht, M.; Asl, A.R.; Zahedi, K.T. Energy Requirement for Cutting Corn Stalks. Int. J. Biol. Biomol. Agric. Food Biotechnol. Eng. 2014, 8, 479-482.

5. Allameh, A.; Alizadeh, M.R. Specific cutting energy variations under different rice stem cultivars and blade parameters. Idesia 2016, 34, 11-17. [CrossRef]

6. Igathinathane, C.; Womac, A.; Sokhansanj, S.; Cannayen, I. Corn stalk orientation effect on mechanical cutting. Biosyst. Eng. 2010, 107, 97-106. [CrossRef]

7. O'Dogherty, M. A review of research on forage chopping. J. Agric. Eng. Res. 1982, 27, 267-289. [CrossRef]

8. McRandal, D.; McNulty, P. Impact cutting behaviour of forage crops I. Mathematical models and laboratory tests. J. Agric. Eng. Res. 1978, 23, 313-328. [CrossRef]

9. Prasad, J.; Gupta, C. Mechanical properties of maize stalk as related to harvesting. J. Agric. Eng. Res. 1975, 20, 79-87. [CrossRef]

10. Pekitkan, F.G.; Eliçin, A.K. The Change of Shear Force and Energy of Cotton Stalk. Agronomy 2018, 61, 360-366.

11. Esgici, R.; Pekitkan, F.G.; Ozdemir, G. Cutting Parameters of Some Grape Varieties Subject to the Diameter and Age of Canes. Fresenius Environ. Bull. 2019, 28, 167-170.

12. Boydaş, M.G.; Çomakli, M.; Sayinci, B.; Kara, M. Effects of moisture content, internode region, and oblique angle on the mechanical properties of sainfoin stem. Turk. J. Agric. For. 2019, 43, 254-263. [CrossRef]

13. Igathinathane, C.; Womac, A.; Sokhansanj, S.; Narayan, S.; Cannayen, I. Size reduction of high- and low-moisture corn stalks by linear knife grid system. Biomass Bioenergy 2009, 33, 547-557. [CrossRef]

14. Azadbakht, M.; Esmaeilzadeh, E.; Esmaeili-Shayan, M. Energy consumption during impact cutting of canola stalk as a function of moisture content and cutting height. J. Saudi Soc. Agric. Sci. 2015, 14, 147-152. [CrossRef]

15. Ghahrae, O.; Khoshtaghaza, M.; Ahmad, D.B. Design and development of special cutting system for sweet sorghum harvester. J. Cent. Eur. Agric. 2008, 9, 469-474.

16. Bernacki, H.; Haman, J.; Kanafojski, C. Agricultural Machines, Theory and Construction; NTIS: Springfield, VA, USA, 1972.

17. Vu, V.-D.; Ngo, Q.-H.; Nguyen, T.-T.; Nguyen, H.-C.; Nguyen, Q.-T.; Nguyen, V.-D. Multi-objective optimisation of cutting force and cutting power in chopping agricultural residues. Biosyst. Eng. 2020, 191, 107-115. [CrossRef] 
18. Nor Mohamed, S.A.; Zainudin, E.S.; Sapuan, S.M.; Md. Deros, M.A.; Arifin, A.M.T. Integration of Taguchi-Grey Relational Analysis Technique in Parameter Process Optimization for Rice Husk Composite. BioResJournal 2019, 14, 1110-1126.

19. Musabbikhah, H.S.; Subarmono, M.; Wibisono, A. Modelling and Optimization of the Best Parameters of Rice Husk Drying and Carbonization by Using Taguchi Method with Multi Response Signal to Noise Procedure. Int. J. Renew. Energy Res. 2017, 7, 1219-1227.

20. Shyam Thapa, M.A.M.; Humphrey, K.; Engelken, R. Optimization of process parameters in the pelletization of crop residues by taguchi-grey relational analysis. Int. J. Agric. Environ. Biores. 2018, 3, 60-74.

21. Deepanraj, B.; Sivasubramanian, V.; Jayaraj, S. Multi-response optimization of process parameters in biogas production from food waste using Taguchi-Grey relational analysis. Energy Convers. Manag. 2017, 141, 429-438. [CrossRef]

(C) 2020 by the authors. Licensee MDPI, Basel, Switzerland. This article is an open access article distributed under the terms and conditions of the Creative Commons Attribution (CC BY) license (http://creativecommons.org/licenses/by/4.0/). 